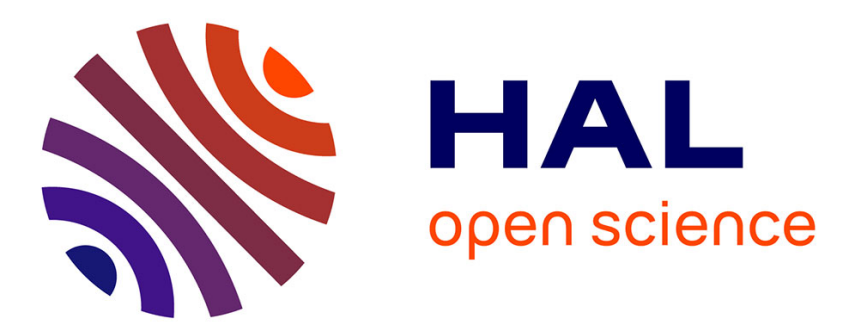

\title{
Social innovation by design in mobile healthcare for sleep disorders
}

Marie-Julie Catoir-Brisson

\section{To cite this version:}

Marie-Julie Catoir-Brisson. Social innovation by design in mobile healthcare for sleep disorders. Design as a catalyst for change, Design Research Society, Jun 2018, Limerick, Ireland. pp.2324-2333 10.21606/dma.2018.264 . hal-01841771

\section{HAL Id: hal-01841771 \\ https://hal.science/hal-01841771}

Submitted on 21 Aug 2018

HAL is a multi-disciplinary open access archive for the deposit and dissemination of scientific research documents, whether they are published or not. The documents may come from teaching and research institutions in France or abroad, or from public or private research centers.
L'archive ouverte pluridisciplinaire $\mathbf{H A L}$, est destinée au dépôt et à la diffusion de documents scientifiques de niveau recherche, publiés ou non, émanant des établissements d'enseignement et de recherche français ou étrangers, des laboratoires publics ou privés. 


\title{
Social innovation by design in mobile healthcare for sleep disorders
}

\author{
CATOIR-BRISSON Marie-Julie $\mathrm{a}^{\mathrm{a}^{*}}$ \\ ${ }^{a}$ Associate Professor of Design and Communication, University of Nîmes, Projekt Lab (EA 7447) \\ * Corresponding author e-mail: marie-julie.catoir@unimes.fr \\ doi: $10.21606 / d m a .2017 .264$
}

\begin{abstract}
This project-grounded research aims at answering a need for research on sleep disorders and connected objects, through an interdisciplinary dialogue between human and social sciences, medical sciences and design. The objective of this article is to answer the following questions: how can social innovation by design sustain the development of innovative medical devices? How can design work to optimize the prevention, the support and the follow-up in sleep medicine? The project aims at creating a digital platform optimizing the circulation of the data, the customer's journey and the communication between patients and care professionals. The research has had a double scientific challenge, carrying on therapeutic education in sleep and digital health literacy, especially in the field of medical computing and mobile devices for chronic diseases. First, the scientific roots and methodology is explained. Then, the methods of inquiry and the results are reported. Finally, a contribution to design research for healthcare is proposed, focusing on the role of design in promoting sleep's hygiene through the creation of suitable services, products, experiences and healthcare environments.
\end{abstract}

Keywords: m-Health; insomnia; service design; digital literacy

\section{Introduction}

This article deals with a project-grounded research currently being developed at the PROJEKT Lab at the University of Nîmes, on service design in mobile healthcare (especially sleep disorders), in collaboration with the University Hospital in Nîmes ${ }^{1}$. Based on an interdisciplinary dialogue between design sciences, information and communication sciences and medical sciences, this research involves, at the same time, interaction design, service design and social innovation by design. Using experimentations and prototyping, the objective is to show that a digital service can be useful to educate and to follow insomniac people up, if it is integrated in a care network and supported by

\footnotetext{
${ }^{1}$ The research is co-managed by Dr Beatriz Abril, Neurologist and Sleep disorder specialist, Dr Gauthier Brisson, General
} 
care professionals. The financial contribution of the University Hospital in Nîmes (Second award won in October 2016 at the Innov'actions Trophy) has made this one-year study possible, to assess the feasibility of the project and to make inquiries with local stakeholders. Research is needed on chronic insomnia and connected objects. In France, insomnia is a public health problem that affects almost $20 \%$ of the population. In spite of the recommendations of the HAS (Haute Autorité de Santé which is French Health High Authority), patients care is limited at any level: access to healthcare, availability of the professionals, lack of educational kit tools, reimbursement for healthcare, and adverse drug reactions. Moreover, connected objects and apps dedicated to sleep are growing faster and faster. They are used by the citizens, without any medical supervision, and are often given up after a few months (Kebs, Duncan, 2015). But their emerging use implies the development of health digital literacy. These technological innovations and the social changes accompanying them make the participation of health professionals, designers, researchers and citizens in the field of mobile healthcare for sleep disorders necessary. Problematics in this study aim to answer the following question: How the design of mobile health technologies in the field of insomnia leads to rethink the cooperation's models between healthcare professionals and patients, the care journey of the patients and the role of the different stakeholders? This article consists in three parts to cope with this complex issue. In the first part, the scientific roots and the methodology are presented. In the second part, the first results of the research are discussed. In the third part, a contribution to design research for healthcare is proposed.

\section{Scientific roots and methodology: social innovation by design and digital social innovation}

To start with, let's introduce the different concept and values of the design research, in order to define the specificity of the methodology.

First, this project-grounded research is part of a specific methodology called recherche-projet (Findeli, 2003), characterized by the fact of articulating a research project and a service design project. It is a kind of action-research ${ }^{2}$ (Rapoport, 1973) to make the experience of the participants better. Considered at the same time as experts of their own experience and beneficiaries of the project, they are involved in the search for solutions.

To be more specific, the methodology is based on an interdisciplinary dialogue between medical sciences, social and human sciences (in peculiar information and communication sciences) and design sciences, as we can see in the diagram below.

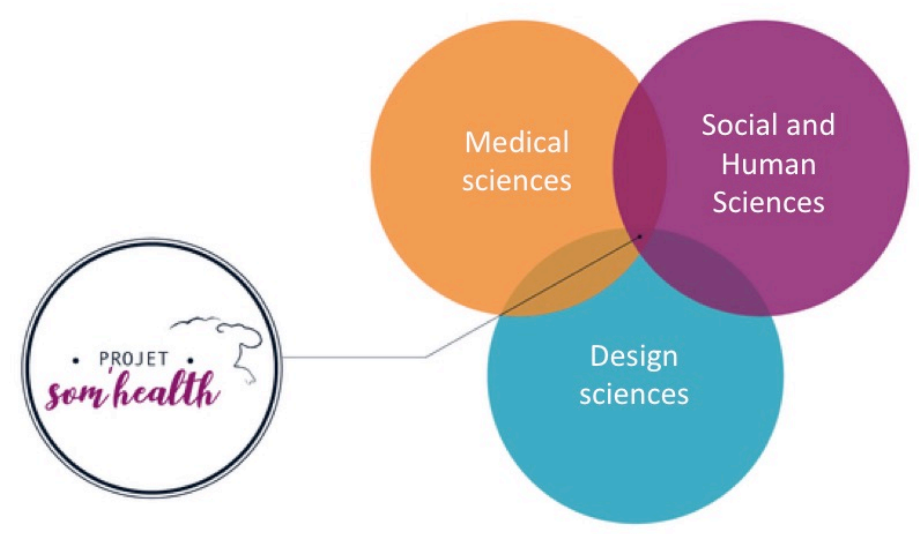

Figure 1 - Interdisciplinary methodology of the project-grounded research

\footnotetext{
${ }^{2}$ According to Robert N. Rapoport (1973, p.115), « action-research aims at making a contribution at the same time to the practical concerns of people being in problematic situations and to the development of social sciences, by a collaboration that connects them according to a mutually acceptable and ethical plan. »
} 
Secondly, it is important to explain the meaning of social innovation through in this research. Social innovation by design is a topical issue in human and social sciences especially in the design sciences. Nevertheless, it is not really new and this trend takes up with the origins of design history (for instance, the works of the Bauhaus, then V. Papanek, A. Findeli). Design sciences may seize the problem of social innovation today because these two fields have in common to study the problematic of uses, and try to stand out from technology and product-centered innovation. This approach gives the patients a power to design and act, beside healthcare professionals and administrations. Thus, digital products and services can be designed for social change, as far as they are designed to create uses and behaviours dedicated to social innovation (Tromp, Hekkert, Verbeek, 2011). It is important to underline the implication of both patients and professionals in this project, to explain how it is possible to reframe patients as persons with active participation in their own healthcare. The objective of the project is to build a human and digital network in which the patients can develop their healthcare and digital skills based on the expertise of their own experience of patients. In addition, healthcare professionals can develop their knowledge in the field of insomnia as well as their digital literacy, by taking part in the service network.

The specificity of this project-grounded research is also based on human-centered-design (Buchanan, 2001). The objective is to go further to the problematic of use to reach social issues involving the designer's responsibility ${ }^{3}$. Human-centered-design "is an on-going search for what can be done to support and strengthen the dignity of human beings as they act out their lives in varied social, economic, political, and cultural circumstances." As a consequence, "the quality of design is distinguished not merely by technical skill of execution or by aesthetic vision but by the moral and intellectual purpose toward which technical and artistic skill is directed. ${ }^{4}$ " In this perspective, the objective of the project-grounded research is to develop a creative ethics of technology that is close to ethics by design, based on the responsibility of the act of design in the proposal of an experiencea-vivre (Vial, 2015) from five key steps in the design process: understanding the experience of the users, using participative methods, relying on a systematic approach (to create a synergy between all the actors), making workshops in order to practice ideation, co-creation or co-design services and prototypes with the beneficiaries, in an iterative way of thinking.

At last, digital social innovation ${ }^{5}$ is also part of the methodology of this project. This approach of technology makes the movement from technological-centered innovation to social and digital innovation possible, in which digital technology is put in the service of the common good for public health interventions.

\section{Methods of inquiry: a qualitative, participative and creative research}

The first step of the design process was dedicated to inquiry, in the field of the public hospital in Nîmes but also in office practice (general practitioner). This methodology was useful to understand and then to make many actors (patients, healthcare professionals and administrations) take part in the healthcare project. It can be considered as a contribution in both research and practice on insomnia because "no study was focused on the cross-personal views of these actors." The qualitative methods were used to collect data on the representations, the practices and the expectations of the participants.

\footnotetext{
${ }^{3}$ Tromp N., Hekkert P., Verbeek P-P., « Design for Socially Responsible Behavior: A Classification of Influence Based on Intended User Experience », Design Issues Vol. 27, N³, 2011, p.3-19.

${ }^{4}$ Buchanan R., "Human Dignity and Human Rights: Thoughts on the principles of Human-Centered Design ", in Design Issues, Vol 15, n³, 2001, p.35.

${ }^{5}$ Our research leads on the values developed in the European community research of DSI : https://digitalsocial.eu

${ }^{6}$ Gaboreau Y., Pricaz F., Cote-Rey A., Roucou I., Imbert P. (2017) « Consensus, controverses et dissensions entre médecins généralistes et patients autour de l'insomnie chronique primaire ", Revue Exercer \#130 Volume 28, Collège National des Généralistes, février 2017, p.52.
} 

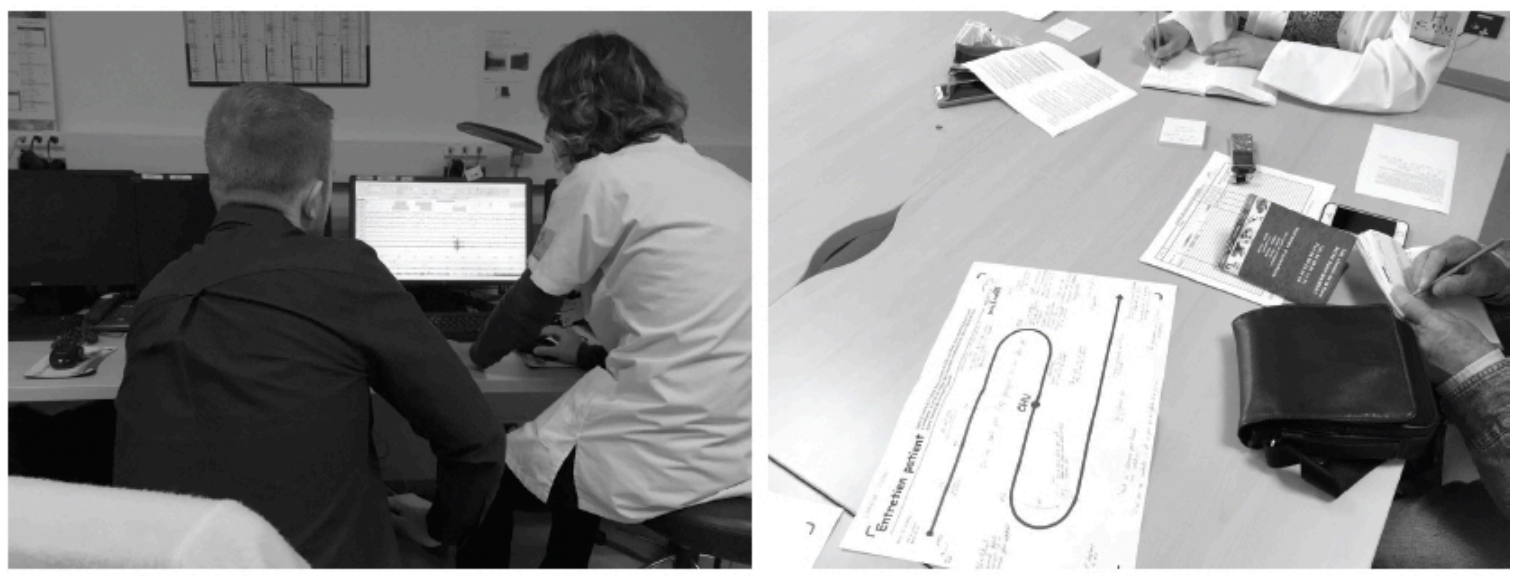

Figure 2 Observation periods and interviews

The inquiry was based on three steps: observation periods, interviews and workshops, from February to June, in 2017. Observations of specialized consultations in the Sleep Medecine Unity of the University Hospital in Nîmes were undertaken with the agreement of the doctors and fifteen patients. Then, semi-structured individual interviews and focus group based on visual and creative methods were organised in the public hospital and in the office of a general practitioner (with doctors, patients, medical secretaries, and also local public administrations (ARS Occitanie, CPAM du Gard). This step was useful to understand the limits, constraints and the specificities of the consultation in medical city office and in the public hospital. It was also helpful to visualise the patient's journey in order to underline the problems between the patients and the touch points of their healthcare journey between public hospital and many healthcare professionals in the city). The analysis of the data collected during the observations period allowed us to design two workshops in April and June based on creative method and co-design.

The first workshop was composed of twelve healthcare professionals (psychologist, general and specialist practitioners) in order to come together the main actors and to understand their actual problems in the insomniac patient's journey and their uses of digital tools and mobile devices. Visual and creative methods were used to make the expression of the participants easier. Visual materials came from two different sources. The participants - especially the general practitioners - were invited to send some photographs of the digital tools they may use in their everyday professional practice. For example, two general practitioners sent us a screen shot of their mobile phone representing the homepage of Klepios (an app for doctors with a synthetic medical index of the main pathologies; see https://www.klepios.com) and Univadis (free medical app and website with medical information, especially on drug interactions; see https://www.univadis.fr). We also gave boards and visual cards representing various digital tools used in medical city office, made by the social service designer of the project. The visual methods used in this investigation were based the same time on the participants', the designer's and the researcher's productions. We let the participants free to cover the boards with notes in order to represent the digital tools for which they did not have any picture. With this methodology, we collected information on the individual practices of twelve healthcare professionals. 

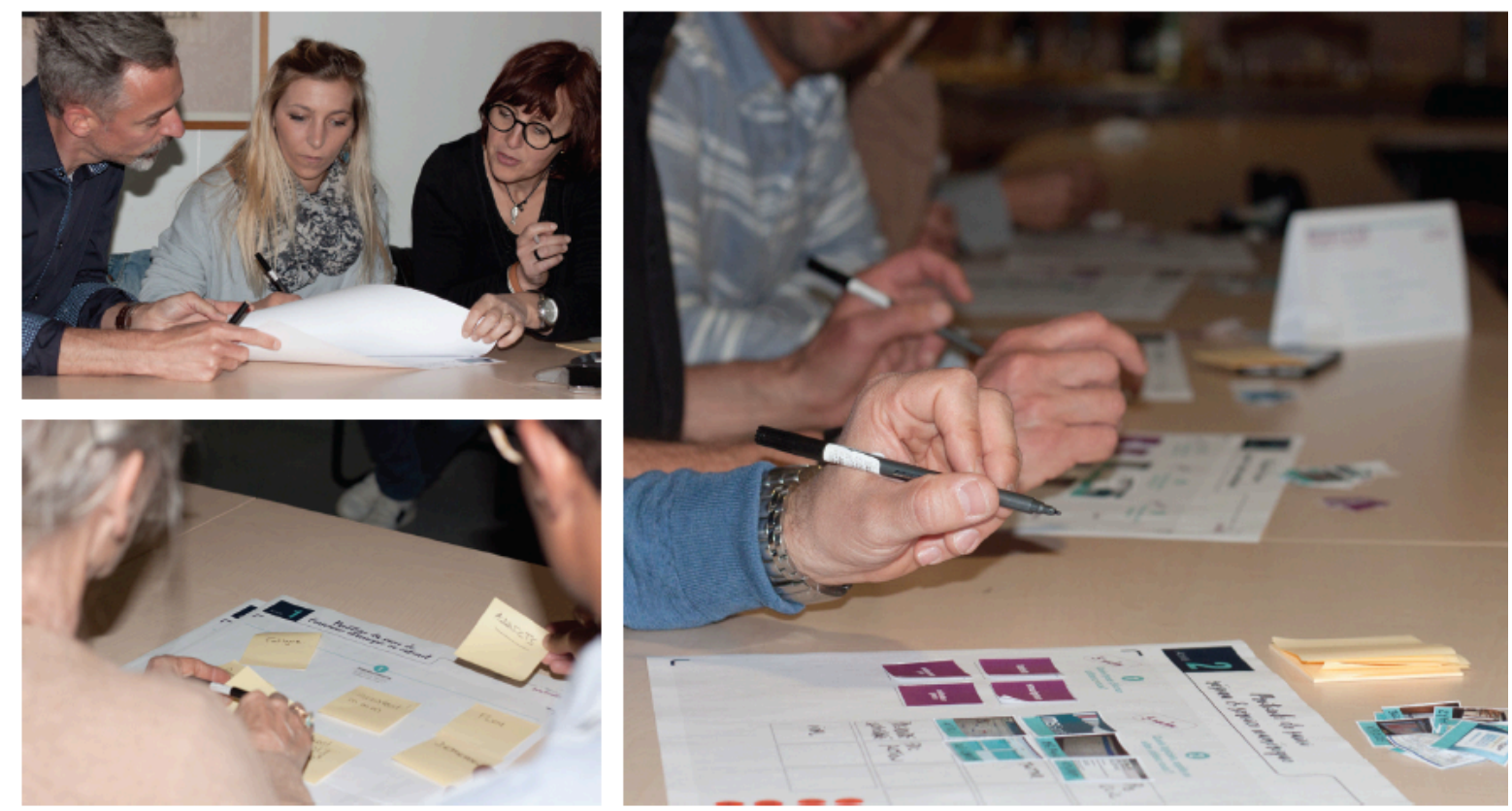

Figure 3 Workshop \#1 April 2017

The second workshop of co-design at the beginning of June was made with patients, healthcare professionals and administrators. Different methods coming from game storming were used, based on activities made to use space as an expression of opinions, and also visual and creative methods. The participants were invited to work in small groups of three or four people, and each team had to mix patients with doctors, and a secretary or an administrator. Visual materials (such as game board, cards, personas, patient care journey, map-tools, map of the network etc.) were prepared by the designer and researcher and proposed to the participants to support their expression by playful and participative materials.

The results of this co-design workshop were very useful, as three maps of the care professionals and insomniac patients network were sketched, in order to express different visions of the sleep institute imagined by the participants. In addition, more than twenty digital tools at the service of the human network were produced, allowing to imagine the digital and healthcare services of the institute, the functions of the website and the connected object used to optimize the prevention, the support and the medical follow-up in sleep medicine.
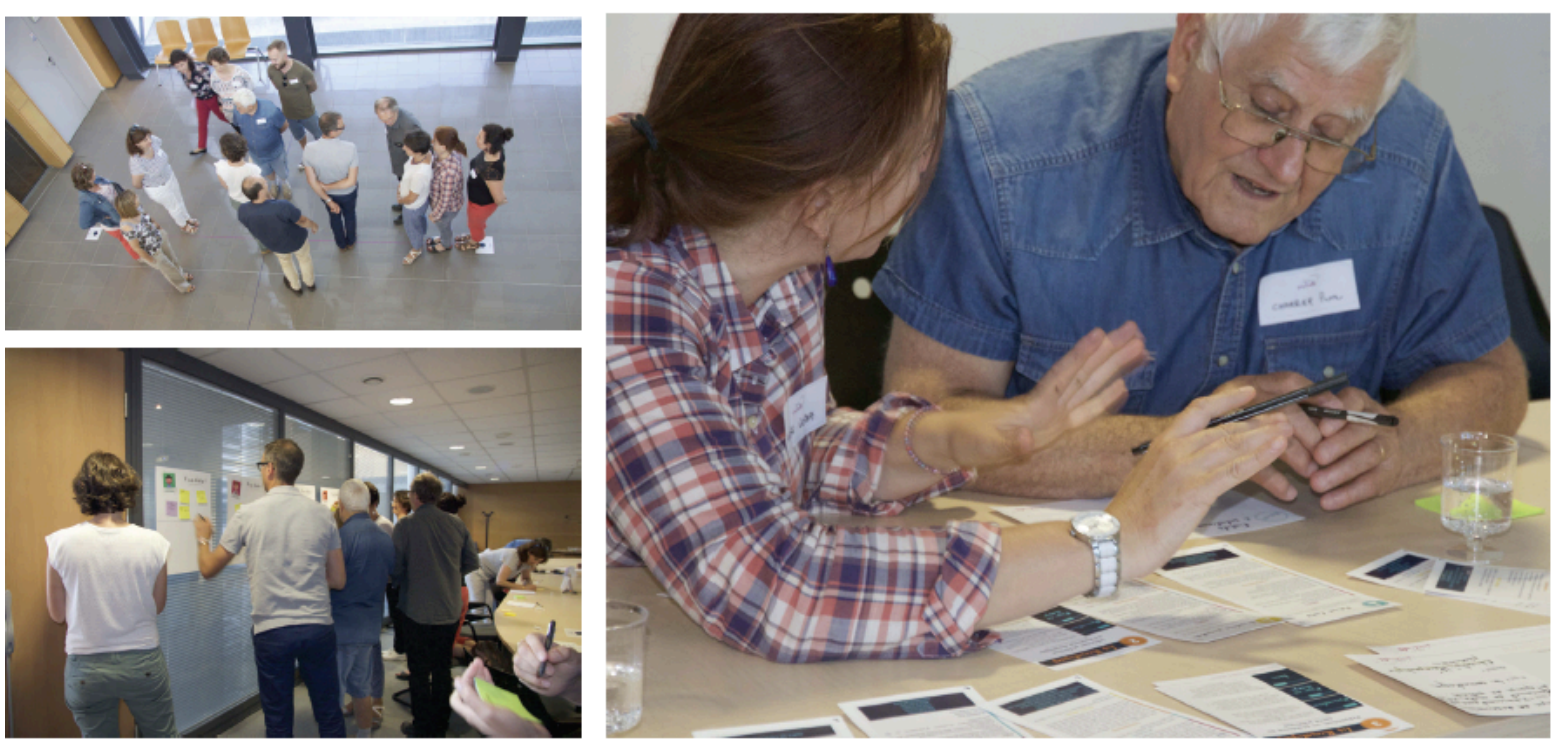

Figure 4 Workshop \#2 June 2017 
The visual methods were relevant to make the voicing of opinions easier and to increase the implication of the participants in the workshops. " This implication can be explained by the fact that visual methods offer participants the possibility to express themselves from several materials that they can mobilize in a free way. ${ }^{7}$ " All the visual and physical materials were used as mediation's support in the workshops, at the service of the methodology of this project-grounded research. Relying on co-design and inclusive design can be a useful way of leading organizational changemaking based on a method to involve participants, who can be care professionals, patients and relatives. This systemic design practice and research is necessary in the field of healthcare because this specific field is a complex field, which combines the interventions of many different stakeholders.

The observations, the interviews and the two workshops allowed to draw and to propose some solutions that can be useful to the research and to the project. The main results accentuated the necessity of 1 / creating a patients and healthcare professionals network to develop therapeutic education and to optimize the patient's care journey; 2 / improve the communication between healthcare professionals, patients and administrations. This network would be based on a digital tool allowing to collect data on the patient, which would serve to develop the research on sleeping disorders within a living lab ${ }^{8}$ (ENoLL, 2008). The data would be visualized, after a work of information design, to inform the patients on their own mechanisms of sleep and improve the understanding and the follow-up of their pathology. A human care professional network in the local community would support the digital network. These results invite us to think about the way the digital technology re-configures the medical practice and the communication between doctors and patients. They also open the reflection on the mutual contributions between information and communication sciences and design sciences.

Moreover, we can list the various project deliverables that we produced during this first year of study. A book - including the results of the enquiry, some recommendations for the design of the institute dedicated to insomnia, more than twenty digital and educational tools for patients and care professionals, and users scenarios - was printed. A pedagogical project was also managed with the students of the Master's programme "Design Innovation Society" (Master DIS) in the University of Nîmes, from October 2017 to January $2018^{9}$ to develop the possible deliverables of the project. The objective of the pedagogical project was to make students understand the complexity of the field of healthcare, and imagine solutions able to change customer's journey, landscape and experience in healthcare through social innovation by design. The student's propositions were useful to give form to the human network that can improve the patient's care journey and to develop the interaction design between the digital network and the connected object dedicated to the data collection on sleep (including a prototype of the web application). A short documentary was produced to explain the project methodology based on social design. A website is also proposed to follow the current events of the project (see: https://projetsomhealth.org).

It is important to finish with the main limits of this experience of project-grounded research in the field of healthcare. We can list three limits: $1 /$ political limits both in the local and national context as chronic insomnia is not considered as a priority in French health policy during this one-year study; 2 / limits in relation with the stakeholders such as representations of patients and care professionals on insomnia and its treatment, fears of change and of technology, access to professionals; 3 /limitations

\footnotetext{
${ }^{7}$ Catoir-Brisson M-J., Jankeviciute L., « Entretien et méthodes visuelles : une démarche de recherche créative en sciences de l'information et de la communication ", Sciences de la société, 92, 2014, p.125.

${ }^{8}$ According to the European Network of Living Labs (http://openlivinglabs.eu): "a Living Lab is about experimentation and co-creation with real users in real life environments, where users together with researchers, firms and public institutions look together for new solutions, new products, new services or new business models."

${ }^{9}$ This pedagogical project was supervised by Marie-Julie Catoir-Brisson, in collaboration with Lucile Haute and Sandrine Pirolles. Participating students were : Younes Gzouli, Marylou Planchon, Emeline Titeux-Flores, Tiphaine Rosier, Alan Shammas, Camille Soulier.
} 
of the methodology, in peculiar for the participative action-research: difficulty to make care professionals (especially doctors and health administrations) participate in the workshops.

\section{A contribution to Design Research for Healthcare}

In this third and last part, a contribution to design research for healthcare is proposed. Our projectgrounded research can be studied to demonstrate how design can improve the prevention and the promotion of sleep's hygiene through the creation of services, products, experiences and healthcare environments. More precisely, the methodology based on systemic design allows us to open the project from a service focused on mobile devices to a project of institute considered as a complex of systems and service design dedicated to insomnia prevention and treatment. A human and digital network of patients and professionals can support the institute. In addition, mobile devices and connected objects can be used to serve various stakeholders. The global solution includes optimizing the patient care journey and the communication between patients and caring professionals through secure information systems and database. Access to the patient's data should be co-defined by patients and care professionals. This peculiarity is very important for the ethic value of the project. But the access to the patient's data will also need to consider the recommendations of the French Health High Authority $\left(\mathrm{HAS}^{10}\right)$ and the legal regulations on data protection in the European Union. The minimal equation of the digital platform is composed of professionals + data + patients. And the final form of the digital network should be suitable to the constraint of information system's interoperability (in peculiar between the softs used in public hospital, city office and public administrations). This technological challenge will be possible only if the social interoperability between the various actors is made possible by the local and national public health authorities. This project of connected objects and sleep medicine affects health public policies. This supported need to improve the development of the project was also recommended by one of the general practitioners in the first April workshop. He noticed the importance of a " political support " to develop a " national information campaign " on chronic insomnia, to strengthen our initiative of network on the fieldwork. This is where design can be useful to develop information and educational kit tools, to sustain sleep hygiene and patients' and care professionals' digital health literacy.

The results of this one-year design research lead us to think about mutual contributions between information and communication sciences and design, and to focus on the contribution of design to the field of human and social sciences.

\subsection{Mutual contribution between information and communication sciences and design}

On the one hand, we can emphasize the links between these to human and social sciences. In design sciences, the project is seen as "the act of design" and the act of design is an "act of communication" (Vial, 2014). It can be analysed from both perspectives: conception and reception, that is to say "the design gesture" and "the effect of design" (Vial, 2015). The act of design refers to the act of communication inherent to any media device. In this project-grounded research, the link between the two sides of the co-construction of the meaning (by designer and user) is analysed with three main approaches that build the specificity of the main researcher's profile: semiotics, communication and anthropology.

Moreover, it is necessary to put the designer's and researcher's roles in a project-grounded research into perspective, especially in the fieldwork. Our experience of this project makes us think that these two approaches are complementary. With the researcher, the designer contributes to the creation of mediation devices that are helpful to the transmission and the collection of information between the participants. The visual materials can be considered as "transitional objects", useful in a "potential environment of skills development ${ }^{11 "}$. These materials build up an environment allowing

\footnotetext{
${ }^{10}$ See the Frame of reference of the best practices on health applications and connected objects published in 2016: http://webzine.has-sante.fr/portail/upload/docs/application/pdf/2016-11/has_ref_apps_oc.pdf

${ }^{11}$ Berten A., (1999), « Dispositif, médiation, créativité: petite généalogie », Hermès 25, Le dispositif, CNRS, p.41.
} 
to develop the necessary conditions to develop the creativity of the participants. In addition, the designer can draw visual synthesis of the enquiry, which can enlighten some characteristics of the qualitative analysis.

On the other hand, the mediation tools produced in and for the project can be considered as case studies in information and communication sciences. These creative tools based on visual methodology contribute to the renewal of the qualitative inquiries in human and social sciences, with different objectives according to the different steps of the project. In the periods of observation, the visual materials can ease the voicing and the expression of the participants. They are useful to collect representations, experiences and data co-produced by stakeholders, designers and researchers. In the workshops, these mediation tools can be used to help the participants give form to their ideas and solutions. In the development phase of the project, visual materials can be helpful to communicate the solutions to the beneficiaries, and to sketch user's scenarios to explain the functions of the complex system of service design, relying on a storytelling focused on a patient experience.

\subsection{Specific contribution of design to human and social sciences in the field of healthcare}

At the end of this one-year study on design and mobile health in the field of sleep medicine, we can underline the advantages of our methodology based on systemic and inclusive design: implication of the participants committed in the co-design process, appropriation of the project and the values of the project, and empowerment in the prevention, the care and the follow-up of chronic insomnia.

The participative design practice and research also allowed the participants to seize the project and to become some contact persons in each community of the local territory. They participated in the distribution of the project in their own networks. To us, this is the minimal condition to make a project dedicated to social innovation in healthcare successful. Indeed, co-design can improve acceptability and adoption of the solutions by the beneficiaries as far as they can take part in the design process.

The qualitative approach allowed us to seize the fears, the expectations and the aspirations of the stakeholders, to be able to propose the most adapted solutions. The contribution of design to human and social sciences in the field of healthcare is to take time, with qualitative and participative methods to understand the constraints and the representations of the stakeholders. This approach is relevant to identify their reluctance and to find solutions to go with the cultural and social change. By understanding the fears and the reluctances of the actors, and putting oneself in the main beneficiaries' shoes - who sometimes live innovation as an order, the qualitative methodologies can accompany the innovation in the field of healthcare to acculturate the professionals and the patients in the collective intelligence based on creative methods, but also in the digital health literacy.

At last, we can distinguish five figures of the designer's mediation role in a project. The designer can also be a "competence connector" (Deni, 2014), a coordinator, a communicator, a facilitator and a translator, able to manage the inter-professional and interdisciplinary dialogue between the multiple stakeholders. New roles for the designer can be identify in the complex field of healthcare. Sleep medicine, as a new cross-disciplinary discipline, offers great challenges for designers to lead multidisciplinary groups and make major decisions that will influence behaviour contributing to longterm prevention and better overall population sleep's hygiene.

\section{Conclusion}

To conclude, this project-grounded research on design and $\mathrm{m}$-Health dedicated to sleep disorders can be considered as an attempt to contribute to the design research on healthcare and wellbeing. The specific contribution is about the systemic design of the project, including many stakeholders and some digital tools at the service of the patients and care professionals network. The systemic 
approach is useful to understand how it is necessary to re-design the whole experience of the patient's care journey, and to design educational kit tools for patients and care professionals, including telemedicine service and mobile health.

The specificity of the project and of the complex fieldwork lead us to build up a methodology based on social innovation by design, to give suitable answers to the questions we identify on the field. In this perspective, this project-grounded research goes forward to object or service design to reach to systemic design of systems and services based on suitable solutions for the main stakeholders. The scientific roots of the research, based on human-centered-design lead us to work on social interoperability between the actors. The solutions are designed to optimize the communication between insomniac patients and care professionals, to improve the patient's care journey, to develop the training of professionals in sleep medicine and therapeutic education, and to develop digital health literacy. The objective of the project is thus to consider the benefits form designing a digital service dedicated to insomnia, which is integrated in a patient and professional network, to improve the implication and sustain the empowerment of insomniac patients in their own pathology.

In addition, we can say that further results could be presented to the DRS Congress in June 2018, as the current development phase has led the scientific team to meet potential partners to develop a prototype of the digital network and the connected objects in the following two years.

To finish with, these two initiatives can also be considered as an attempt to underline the role of design in prevention and wellbeing in sleep medicine.

\section{References}

Al Dahdah, M. (2014). MHealth : l’information de santé ubique ?, Le Temps des médias 2014/2 ( ${ }^{\circ} 23$ ), 52-65.

Bartlett,e DJ. Marshall, NS. Williams, A. Grunstein, RR. (2008). Predictors of primary medical care consultation for sleep disorders. Sleep med, 9, 123-130.

Berten A. (1999). Dispositif, médiation, créativité : petite généalogie, Hermès 25, CNRS, 33-47.

Caccamo, E., Catoir-Brisson M-J. (2016). Métamorphoses des écrans : invisibilisations, Interfaces numériques $n^{\circ} 5 / \mathrm{Vol} 2$, Editions design numérique, juin 2016.

Catoir-Brisson, M-J. (2017). Du design d'interaction au « textile social »: approches communicationnelle et sémiotique d'un média tangible, MEI 41, Design et communication. Retriewed from http://meiinfo.com/revue/40/209/

Catoir-Brisson M-J., Jankeviciute L. (2014). Entretien et méthodes visuelles : une démarche de recherche créative en sciences de l'information et de la communication, Sciences de la société, 92, 111-127.

Conseil National de l'Ordre des Médecins. (2015). Santé connectée: de la e-santé à la santé connectée, Livre blanc du CNOM, janvier 2015.

D. Reay S., Collier G., Douglas R., Hayes N., Nakarada-Kordic I., Nair A. \& Kennedy-Good J. (2017). Prototyping collaborative relationships between design and healthcare experts: mapping the patient journey, Design for Health, Vol 1, 65-79.

Deni, M. (2014). Le design de services: projeter le bien-être, Communication \& organisation 2/2014 ( $\left.{ }^{\circ} 46\right)$, 129-142.

Duret F., Floriot D. (2012). Attentes des patients sur la prise en charge de leur insomnie chronique au sein de l'arc alpin. Thèse de médecine: Université de Grenoble.

European Network of Living Labs (2008): 'Open Living Labs', available online at http://openlivinglabs.eu.

E. Wildevuur S. (2017). Could health learn from design?, Design for Health, 1/ 2017, 59-64.

Findeli, A. (2015). La recherche-projet en design et la question de recherche : essai de clarification conceptuelle, Sciences du Design \#1, 43-55.

Gaboreau Y., Pricaz F., Cote-Rey A., Roucou I., Imbert P. (2017), Consensus, controverses et dissensions entre médecins généralistes et patients autour de l'insomnie chronique primaire, Revue Exercer \#130 Volume 28, Collège National des Généralistes Enseignants, 2017, p.52-59. Retriewed from https://www.exercer.fr/numero/130/page/52/

Jones P. (2013). Design for care: innovating healthcare experience, New York, Rosenfeld Media, Retriewed from http://tandfonline.com/doi/full/10.1080/24735132.2017.1295541 
Krebs, P., Duncan DT. (2015). Health App Use Among US Mobile Phone Owners: A National Survey ", JMIR MHealth UHealth, Retriewed from https://www.ncbi.nlm.nih.gov/pmc/articles/PMC4704953/

Lagger, G. Pataky, Z. Golay, A. (2010). Efficacy of therapeutic patient education in chronic diseases and obesity. Patient Educ Couns, 79, 283-286.

Moggridge, B. (2007). Designing Interactions, The MIT Press.

Norman D. (2012). Design émotionnel, Bruxelles, De Boeck.

Rapoport R.N. (1973), "Les trois dilemnes de la recherche-action”, Connexions n7, 115-131.

Tromp N., Hekkert P., Verbeek P. (2011). Design for Socially Responsible Behavior: A Classification of Influence Based on Intended User Experience, Design Issues Vol. 27, N³, 2011,.3-19.

Vial, S. (2014) Le design, un acte de communication? Hermès \#70, 174-180.

Vial, S. (2015). Le design. Que sais-je? Paris: PUF.

About the Author:

Marie-Julie Catoir-Brisson works on mHealth and social innovation. Her recent works deal with digital interfaces, connected objects, information and interaction design, which she approaches on a critical perspective, from several knowledges: design, semiotics, intermediality, communication's anthropology, visual methods. 